\title{
La distopía del presente: apuntes sobre Jinete a pie, de Israel Centeno*
}

Recibido: 18/09/2018 | Revisado: 18/11/2018 | Aceptado: 27/11/2018

DOI: $10.17230 /$ co-herencia.16.30.3

\author{
Daniel Fermín** \\ danielfermin10@gmail.com
}

\begin{abstract}
Resumen Este artículo propone una lectura analítica de la novela Jinete a pie (2014), de Israel Centeno, que forma parte del grupo de obras, publicadas en los últimos años, que vislumbran un futuro distópico para Venezuela. Inicialmente se repasa el origen de la distopía como género literario y sus antecedentes utópicos, así como el auge de la novela distópica venezolana en el siglo xxI; luego se estudian las características de Jinete a pie, para analizar la construcción de una distopía que remite a una Caracas arrasada por la violencia y su relación con el contexto venezolano actual.
\end{abstract}

\section{Palabras clave:}

Distopía, utopía, género literario, literatura venezolana, literatura latinoamericana contemporánea.

\section{Dystopia of the present: notes on Jinete a pie by Israel Centeno}

\begin{abstract}
This paper proposes an analytical reading of the novel Jinete a pie (2014) by Israel Centeno, part of the group of works published in recent years which envision a dystopian future for Venezuela. First, the origin of dystopia as a literary genre as well as its utopian background is reviewed and the boom of the Venezuelan dystopian novel in the 21 st century is discussed. Then, the features of Jinete a pie are examined in order to analyze both the construction of a dystopian narrative that refers to a Caracas devastated by violence and its relationship with the current Venezuelan context.
\end{abstract}

\section{Keywords:}

Dystopia, utopia, literary genre, Venezuelan literature, contemporary Latin America literature.
* El presente artículo forma parte del proyecto de tesis "La novela distópica en la Venezuela contemporánea (1999. 2018)", para el Programa de Doctorado Interuniversitario en Comunicación, de las universidades de Cádiz, Huelva, Málaga y Sevilla. Fecha de inicio: 2016; fecha de finalización: 2020.

** Máster en Escritura Creativa por la Universidad de Sevilla, España. ORCID: 00000001-8918-9572. 


\section{Introducción: sobre los orígenes de la distopía}

El origen de la palabra "distopía" hay que buscarlo en el término "eutopía". No se pretende resumir aquí la ingente bibliografía que existe sobre este último. Sería una tarea imposible, por no decir utópica, y ajena al objetivo central de este artículo. Bastará con decir que la eutopía, hoy más conocida por el neologismo griego "utopía", acuñado por Tomás Moro en el siglo XVI, significa literalmente "no lugar".

La historia de la utopía ha generado innumerables estudios que han pretendido definir el término. Dice Lyman Tower Sargent (1975) que el principal problema al que se enfrenta cualquier persona interesada en el estudio de la literatura utópica es la definición o la delimitación del campo. El término es tan amplio, que obliga a restringir su uso. Raymond Trousson, en Historia de la literatura utópica. Viajes a países inexistentes, propone una definición:

Proponemos que se hable de utopía cuando, en el marco de un relato (lo que excluye los tratados políticos), figure descrita una comunidad (lo que excluye la robinsonada), ${ }^{1}$ organizada según ciertos principios políticos, económicos, morales, que restituyan la complejidad de la vida social (lo que excluye la edad de oro y la arcadia), ya se presente como ideal que realizar (utopía constructiva) o como previsión de un infierno (la antiutopía moderna) y se sitúe en un espacio real o imaginario o también en el tiempo o aparezca, por último, descrita al final de un viaje imaginario, verosímil o no (1995, p. 54).

Trousson diferencia así la utopía como género, de la utopía como idea o concepción mental. Tal distinción pretende evitar que en un mismo estudio se mencionen como iguales una novela utópica y un ensayo político con espíritu utópico.

Algunos críticos coinciden en que el relato fundador de la utopía se halla en Tomás Moro (1516). Sin embargo, la utopía tendría su prehistoria en los griegos. Gabriel Saldías, en En el peor lugar posible: teoría de lo distópico y su presencia en la narrativa tardofranquista española (1965-1975) (2015), sostiene que la génesis de la eutopía debe

1 Se entiende por robinsonada "la aventura de un hombre aislado o de un pequeño grupo de hombres civilizados apartados de la sociedad" (Trousson, como se cita en Calatrava, 2010) (Nota del autor). 
ser rastreada en La República de Platón. Russell Jacoby (como se cita en Saldías, 2015, p. 27), en cambio, afirma que se encuentra en Los trabajos y los días de Hesíodo.

Moro, con su singular obra, viene a ser el autor que popularizó el término, lo que en comparatismo se llama "monogénesis": a partir de una obra se constituye un género y se definen las obras anteriores a ellas (Trousson, 1995). No fue sino hasta el siglo XVIII cuando la palabra "utopía" comenzó a hacerse común. Hoy se aplica como sinónimo de lo quimérico, de lo ideal, lo imposible o lo inalcanzable.

La característica principal de la utopía es su insularidad o aislamiento. La Utopía de Moro es una isla, mientras la Ciudad del Sol de Tomás Campanella (1953) es una llanura. Otras características de la utopía son: tiene un sistema económico cerrado que desprecia el dinero y el comercio; un funcionamiento político regular, sin disidentes ni conflictos; un personaje legislador que instaura el orden; una sociedad igualitaria, sin clases sociales tradicionales. La utopía tiene la felicidad colectiva como clima dominante. Se caracteriza por reflejar lo que se supone debe ser una sociedad ideal, o mejor a la que vivimos.

El deseo de construir esa sociedad ideal que se basa en la obtención de la felicidad ha dado paso, con el transcurso de los años, a su antítesis: la distopía. Gregory Claeys (2011) dice que la distancia entre utopía y distopía puede parecer pequeña en ocasiones. Nace como consecuencia directa de un género que plantea una quimera, plagado de ideales imposibles de realizar.

Andreu Domingo, en su ensayo Descenso literario a los infiernos demográficos. Distopía y población, señala que:

La distopía, por oposición a la utopía, es el relato del peor de los mundos posibles, que se fragua como género literario a medio camino entre la sátira política y la tragedia a finales del siglo XIX y principios del Xx como reacción a las utopías políticas y a las literarias que las sustentaban (2008, p. 15).

Algunos estudiosos señalan que el economista John Stuart Mill fue el primero en utilizar la palabra "distopía" en un parlamento realizado en la Casa de los Comunes el 12 de marzo de 1868 (Trahair, como se cita en Domingo, 2008, p. 23). No fue hasta 2014 cuando la Real Academia Española incluyó el término "distopía” en su diccionario. 
A diferencia de las utopías, las distopías proyectan un futuro indeseable, en el cual la sociedad ha fracasado. Si bien una novela siempre retrata el tiempo en el que se escribe, sin importar que sea histórica o de ciencia ficción, las distopías tienen un marcado tono de crítica política y social al contexto del autor. Encuentran en las crisis, en presentes que pasan de lo perfecto a lo infernal, un aliado. "La distopía denuncia o pone sobre la mesa la terrible realidad de lo que aún no ha llegado a ser, pero ya está ahî”, dice Domingo (2008, p. 25), quien destaca que tres obras clásicas del género -Nosotros de Yevgueni Zamiatin, de 1921; Un mundo feliz de Aldous Huxley, de 1932; y 1984, de George Orwell, de 1949— compartan ser fruto del desencanto que provocó la dictadura soviética que siguió a la Revolución de Octubre de 1917.

Fernando Reati, en su ensayo Postales del porvenir: la literatura de anticipación en la Argentina neoliberal, señala que "después de dos sucesivas guerras mundiales en el siglo Xx, la distopía [...] reemplaza a la utopía como manifestación central de la literatura futurista y se impone casi como el único tipo creíble de anticipación" (2006, pp. 18-19).

Gregory Claeys, en Utopía: historia de una idea (2011), asegura que la aparición histórica de las dictaduras fascistas y comunistas en el siglo XX tiene su reflejo en la importancia que adquiere el distopismo en algunos textos literarios de la época. Así, la ficción distópica vislumbra el fracaso de los proyectos utópicos. Toma los problemas de su época para radicalizarlos y crear un mundo en el que resulta indeseable estar.

Si la utopía, a partir de los fallos de una sociedad, imagina lo que dicha sociedad debería ser, la distopía funciona como un llamado de atención, un aviso de lo que está por venir si se sigue ese camino. Escribe Trousson:

La mayoría de las antiutopías nacieron después de la Primera Guerra Mundial, algunas después de la Segunda: con eso está dicho hasta qué punto su pesimismo es tributario de las circunstancias históricas. El nacimiento de las grandes dictaduras modernas, la oposición de los grandes bloques políticos, la experiencia concentracionaria, la Guerra Fría, la superproducción anárquica, el dominio cada vez mayor por parte de una técnica deshumanizada, el "arte" de embrutecer a las 
masas, todo ello, en batiburrillo, nutre la antiutopía, cuya esencia es el miedo, el escepticismo desengañado (1995, p. 311).

Establecer el punto de partida de la distopía como género literario tampoco es una tarea fácil. Algunos estudiosos, como Claeys (2011), señalan que la distopía se empieza a constituir como subgénero hacia finales del siglo XIX.

La falta de una definición hizo que muchas obras antecedentes a lo que hoy se conoce como "distopía" fueran clasificadas, en su momento, solo como ciencia ficción. H. G. Wells experimentó con diversas formas distópicas en La máquina del tiempo (1895); Erewhon o tras las montañas de Samuel Butler (1872) y El talón de hierro de Jack London (1908) también podrían mencionarse en ese grupo de novelas con elementos distópicos antes de que la distopía se estableciera como género.

A partir de la mitad del siglo xx, la novela distópica alcanza su auge. Aparecen títulos, hoy referentes del género, como 1984 de George Orwell (1949), La pianola de Kurt Vonnegut (1952), o Fahrenheit 451 de Ray Bradbury (1953).

Yuli Kagarlitski señala (como se cita en Martorell Campos, 2015, p. 97) que la novela distópica representa un examen crítico del progreso, y que por eso no podía aparecer antes de que se formulara la idea del "progreso", antes del siglo XVIII. Así, las guerras mundiales, el cambio climático o el calentamiento global, el capitalismo, las dictaduras o las crisis políticas han creado un escenario propicio para la proliferación de novelas distópicas.

\section{Sobre el auge de la distopía en Venezuela}

La literatura venezolana del siglo XXI ofrece testimonios de la crisis que afecta a ese país. La llegada de Hugo Chávez Frías a la presidencia de Venezuela en 1999 vino sucedida por una crisis política y social, que se ha agudizado en los últimos años con el mandato de Nicolás Maduro Moros: incremento de la delincuencia (Agencia EFE, 2017), debacle económica (Europa Press, 2018), escasez de productos básicos (El Nacional, 2017), protestas callejeras (El Nacional, 2018), migración masiva (Agencia EFE, 2018). Ese contexto ha coincidido con el aumento de novelas distópicas escritas por venezolanos. 
En el siglo xx, la práctica de la novela distópica en Venezuela no es muy notoria. Una cronología del género hasta entonces, apenas tendría escasos títulos. Algunos estudiosos de la ciencia ficción, como Richard Montenegro (2017), señalan que El regreso de Eva, de Federico León Madriz (1933), firmada bajo el seudónimo Pepe Alemán, es la novela que inaugura el género en la literatura venezolana. Desde ese momento, pocos autores de ese país han incursionado en universos prospectivos. Las novelas 1998, de Francisco Herrera Luque (1992), y Dóctor, de Carlos Moros Puentes (1998), podrían incluirse en la corta lista de obras distópicas venezolanas publicadas en el siglo pasado.

No obstante, el listado crece en el nuevo milenio. Éxodo al pacífico, de Darío Campo (2004) — sobre la migración de un grupo de personas de las costas venezolanas a causa de un desastre natural—; Nocturama, de Ana Teresa Torres (2006) — protagonizada por un hombre que sufre del "Síndrome de Identidad Aleatoria" e intenta recuperar su memoria ante el acoso de bandas como "Los Guardianes de la patria”-; Las peripecias inéditas de Teófilus Jones, de Fedosy Santaella (2009) — la historia de un gato que sobrevive en una sociedad que no permite animales, liderada por el "Supremo Presidente"-; Entrevista a Mailer Deamon, de Doménico Chiappe (2007) - acerca de un hombre que trabajó para "Marc Ji el pensador que trajo la paz al mundo"-; Los vengamientos del ejército justiciador, de Ana Rosa Angarita Trujillo (2015) — sobre un ejército que decreta transformar a los blancos en indios o negros-; El reino de arena, de Andrés Volpe (2016) —que parodia el discurso épico venezolano del siglo XIX en un escenario postapocalíptico-; Seguros de justicia, C. A., de Rodrigo Sojo Montes (2016) — que plantea una sociedad en la que los criminales cuentan con seguros médicos para garantizarles todos sus beneficios-; El infinito de la estupidez humana, de Emma Casablanca (2016) —una historia contada a dos voces acerca de "La Nación", un país en ruinas luego de años de guerras, epidemias y la presencia de "El Partido"-; o El amor es más frío que la muerte, de Ednodio Quintero (2017) — las memorias de un personaje que sobrevive en un país asolado por la peste-, son ejemplos de obras escritas por autores venezolanos en años recientes, en las que se refleja un horrible porvenir que remite, en gran parte, a la actualidad de ese país. Jinete a pie, de Israel Centeno (2014), la novela que se analiza 
en este artículo, se ubica en ese género de la ficción prospectiva que suma títulos en Venezuela.

Violeta Rojo, en "Las heridas de la narrativa venezolana contemporánea" (2016), señala que, con pocas excepciones, la narrativa venezolana es realista y suele mostrar los sucesos pasados o presentes de ese país. Explica Rojo que la inmigración, la violencia y ciertos eventos de finales del siglo XX y principios del XXI han determinado los temas de las obras literarias.

Las distopías, sin embargo, también abordan desde otra perspectiva esa realidad. Hay artículos que ya han analizado algunas obras del género en Venezuela. Adrián Hernández, en "El juego del futuro vaticinado: estudio alegórico de Venezuela en la novela Nocturama" (2018), estudia el paralelismo que hay entre la realidad de ese país y la ficción escrita por Ana Teresa Torres; Belkis Suárez, en su tesis La representación de la ciudad y el discurso de la violencia en la literatura latinoamericana contemporánea: Medellín, Caracas y Río de Janeiro (2011), analiza la representación de urbes distópicas en Nocturama, de Torres, y La casa del dragón (2004) y Bengala (2005), ambas de Centeno.

La obra literaria de Centeno incluye novelas y relatos. Ha obtenido, entre otros, el Premio Municipal de Caracas 1992 y el Concurso Anual de Cuentos de El Nacional 2003. Debutó en 1992 con la novela Calletania. Luego le siguieron El rabo del diablo y otros cuentos (1993), Hilo de cometa y otras iniciaciones (1996), Exilio en Bowery (1999) y Criaturas de la noche (2000). En 2002 publicó El complot, una ficción política enmarcada dentro del género de la ucronía, y en 2004, la ya referida novela erótica La casa del dragón. Su obra se completa con una serie de títulos — ocho, hasta la fecha- publicados en España, Venezuela y Estados Unidos, en los que el contexto venezolano y la violencia desempeñan un papel importante en sus tramas.

Valmore Muñoz Arteaga, en su artículo "Repaso a la narrativa de Israel Centeno", analiza dos elementos presentes en la obra del autor:

Las calles de las ciudades de Centeno se vuelven de pronto caminos tortuosos que se abren en el cuerpo de los personajes. Ciudad y hombre se combinan para contarse, para descubrirse en la ira de vivir chupando de las ubres apolilladas del caos. Un caos cuyas dimensiones son las mismas que el fracaso de las utopías con las que se habían 
llenado de esperanzas una juventud que esperaba con euforia el advenimiento de tiempos mejores [...] Centeno mete sus manos en su realidad contemporánea y desde allí emprende el tejido de sus historias. Probablemente, busca descender hacia el infierno de esa violencia colectiva para fustigarla, para encerrarla en los territorios de una hoja en blanco y así poder, ilusoriamente, dominarlas (2009, pp. 51-52).

\section{Sobre la trama y la estructura de la sociedad en Jinete a pie}

Jinete a pie es una novela distópica en la que se narra la historia de un hombre que intenta sobrevivir en una Caracas en ruinas, dominada por hordas de motorizados. Roberto Morel, el protagonista, un antiguo profesor, sufre, al igual que el resto de personajes, de desmemoria: poco se sabe con certeza del pasado de cada uno de los individuos que habitan en la ficción; sin embargo, Morel está obsesionado en rescatar los recuerdos de sus viejos romances. Pero Jinete a pie es más que un relato de amores perdidos. Lo que destaca de la obra es la recreación de un universo decadente, en el que predomina la miseria y la violencia.

La sociedad de Jinete a pie se estructura en dos grupos: los motociclistas y los peatones. Estos se someten al control de aquellos. Visten atuendos polvorientos, pantalones viejos, zapatos romos. Viven en casas en ruinas o jardines abandonados. Solo pueden salir a la calle después de las 7:00 de la mañana. Tienen bonos que pueden canjear por café en panaderías administradas por motorizados, a las que deben entrar sin sonreír ni mostrarse excesivamente sumisos. Se alimentan con té y turrones de calabaza, y consumen yerbas alucinógenas. Tienen prohibido preparar café en los lugares que habitan. Si el olor se expande, los motorizados imponen su castigo. Por regla general, no se atreven a ir más allá de la zona en la que se circunscriben:

Tenían prohibido dejarse ver en multitudes, no debían salir más de dos o tres por la misma acera, no más de 10 por la misma avenida, nunca más de cinco en un café, en todo caso, era necesario mantenerse desperdigados, como un rebaño sobre el pavimento y en los lotes abandonados de los jardines, entre los rosales secos, bajo las sombras de los ficus (Centeno, 2014, p. 43). 
Los motociclistas imponen su poder mediante la violencia. Tienen derecho a abrir una panadería; a vender bollos de pan de jamón, dulce y café; a vestir bluyines, guantes y chaquetas de cuero; a sentarse en las terrazas de las panaderías; a vivir en las casas al otro lado del fuerte; a andar en grupos; a tener una ballesta y matar a un peatón si no cumple las normas. "Se podía ir en moto de dos maneras. Una de ellas llevando el volante y la otra, detrás, en el puesto de quien dispara, muy pegado al conductor" (Centeno, 2014, p. 24). Si no se le renueva su carnet para andar en moto, pierde sus derechos, y pasa a ser uno más de los peatones, de los que sobreviven entre los escombros. "Lo verán a su lado y se harán los desentendidos, no lo reconocerán, o sí, pretenderán no hacerlo, sin derechos todos somos iguales, dice la gente, es la igualdad posible" (Centeno, 2014, p. 12).

La Caracas futura imaginada por Centeno se divide por cantones - "una república de unas pocas manzanas, cuatro avenidas y un cerro" (Centeno, 2014, p. 109)—, separados cada uno por altos muros y laberintos que fragmentan la ciudad. El tiempo no se mide en días ni horas, sino en tazas de café o té. El escenario en el que se desarrolla la trama es la antigua urbanización Altamira, de la que quedan unos pocos elementos reconocibles. La plaza Altamira y su obelisco, ícono de la zona, ya no existen. Ha sido demolida por una explosión. En su lugar, solo hay un cráter y algunas ruinas:

[...] más adelante, si alguien sobrevive el final del mundo y retorna a estos lugares donde reinaron los cantones, sabrá decir que allí está fragmentado un mediocre obelisco que le dio sentido al paisaje e hizo de aquel punto unos de los lugares más hermosos de la ciudad (Centeno, 2014, p. 118).

El cerro El Ávila, otra de las referencias de Caracas, sirve como frontera. "Más allá de los puestos del cerro nadie sabía con exactitud qué ocurría, de allá cruzaban leyendas, nada exacto, cuentos aterradores con finales trágicos" (Centeno, 2014, p. 88). De ese modo, los personajes se ven encerrados en pequeñas zonas, parecidas a "cajas chinas". Escapar tampoco resulta fácil: de evadir a los motociclistas se encontrarán con un laberinto por el que, si logran salir, llegarán a otro de los tantos cantones que existen, con otras reglas y estructuras. Si un peatón transgrede los límites, la caza está permitida. A esa caza se le llama "safaris". En ellos, grupos de motorizados se dedican a asesinar peatones. 
Así, la ciudad de Jinete a pie tiene características de dos de los modelos que Reati (2006) señala como propias de la ficción prospectiva: la ciudad postapocalítica y la ciudad panóptica. Según Reati, "existe una rama de la literatura de anticipación que opta por imaginar el mundo tras una gran catástrofe y que muestra un futuro postapocalíptico tenebroso y virtualmente insoportable en contraste con el mundo perdido" (Reati, 2006, p. 124). Se trata de espacios que imaginan un colapso urbano (Oeyen, 2011). Centeno muestra una Caracas de terrenos baldíos, calles solitarias y edificios en ruinas, sin necesidad de introducir contingencias nucleares, tecnológicas, ecológicas, extraterrestres o biológicas propias de las distopías estadounidenses. Esa misma Caracas fantasma también puede ser calificada de panóptica-caracterizada por un sistema de vigilancia propio de la sociedad de control-, por la vigilia que ejercen esos jinetes a dos ruedas sobre los peatones y por hacer de la ciudad una prisión para quienes sobreviven en ella.

Recogerse temprano era de rigor, volver a los lotes de terrenos abandonados, a las casas que permitían habitar, no estar más tiempo del necesario expuesto a los motorizados que comenzaban la última patrulla del día. Ellos podían decidir cuándo abrir la temporada de caza (Centeno, 2014, pp. 89-90).

\section{Sobre el presente y el pasado de la ficción}

No hay datos precisos de cómo se llegó a la situación del presente de Jinete a pie. La desmemoria colectiva que sufren los personajes impide cualquier tipo de certeza. Lo que conocemos, se debe a recuerdos difusos que el narrador introduce en diversos momentos. A través de ellos se sabe que el apocalipsis no vino dado por ningún cataclismo natural, sino que fue rápido y progresivo, provocado por el hombre:

¿Cómo empezó todo? El flaco recuerda la tarde caótica, el rumor que se acrecentaba segundo a segundo; un nuevo crack, una caída de la bolsa, la profundización del proceso, líderes asesinados. Otros recuerdan a los motociclistas tomar las calles, lanzarse contra todo lo que circulase en cuatro ruedas o fuese a pie; se lanzaban como kamikazes contra ellos, muchos murieron, se creían la reserva de la revolución que caía, ¿Y por qué caía la revolución? Soltó uno 
entre dientes, cayeron los precios, se vino el mundo abajo y encima de nosotros cayeron los precios, no tenemos memoria, y eso es un recuerdo, no podemos confiar en el recuerdo (Centeno, 2014, p. 89).

Centeno pone el énfasis en el olvido de los personajes. Deja duda de la veracidad, o no, de esos hechos pasados. La existencia de un diario tal vez devele detalles de lo que sucedió antes de la debacle. Los sobrevivientes olvidaron su propia historia: Roberto Morel, el protagonista, no tiene claro si antes fue profesor de historia del arte, de música o de literatura, y cree ver en cada mujer a sus viejos amores, a Adriana, a Verónica o a Alexandra.

El presente caótico contrasta con el pasado del protagonista, una época que se extraña con nostalgia:

Recuerdo las avenidas, el ruido de las calles, diverso, apabullante, la gente baja de los autos, sale de los comercios, las puertas de las tiendas, los centros comerciales, fuimos una linda ciudad [...] Ahora recuerdo desde la supervivencia, desde el ghetto, desde la inexistencia, con necesidad de causarme dolor, desde el lugar único de la derrota (Centeno, 2014, p. 14).

Esa "linda ciudad" que Morel recuerda dio paso de forma abrupta a la Caracas decadente en la que se desarrolla la historia. Los motorizados destruyeron algunos lugares de la urbanización, la gente comenzó a saltar de los edificios, estos se convirtieron en ruinas, los aviones desaparecieron y la ciudad quedó fuera de las rutas comerciales. Se acabó con los disidentes, los que se quedaron se convirtieron en motorizados o terminaron sometidos como peatones. Otros, los que pudieron, huyeron.

La migración —una de las heridas de la narrativa venezolana contemporánea, según Violeta Rojo (2016)—, el irse a lugares en los que no llegó el colapso, también se cita en la ficción. Los personajes echan de menos el vivir en un sitio donde se puede llevar una vida normal:

Se hablaba mucho de los lugares a donde habían huido los hijos, los hijos jóvenes. Ellos mandaban mensajes, decían que vivían en un mundo redondo, como lo habían conocido antes del colapso, no era perfecto, pero allí convivían todos, cada quien tenía derechos, había justicia imparcial, un sistema instituido. ¿Habrá sobrevivido algo? Se preguntaban los peatones mordiendo las palabras, entre dientes, en los 
alrededores de La Flor de Altamira. ¿Más allá de los cantones el mundo sigue igual? ¿Por qué no nos rescatan? Somos sus padres o sus tíos, sus hermanos que no pudieron ponerse a salvo. Ya no cabemos, no somos posibles (Centeno, 2014, p. 89).

Los servicios y derechos se eliminaron poco después del colapso, reinó la anarquía en los cantones:

[...] eso es lo que recuerda, la crisis de la energía, las medidas de emergencia, los sucesivos golpes de Estado, la gente organizada en cantones motorizados para la defensa de la patria, las opciones, las huidas (Centeno, 2014, p. 72).

Los personajes se dedican a sobrevivir en un mundo en el que apenas tienen las condiciones para hacerlo. El asesinato de uno de los motoristas a manos de Roberto Morel reactiva los "safaris", la caza de peatones, que habían sido suspendidos. Los personajes, a partir de entonces, se dedican a huir entre iglesias abandonadas, altos muros y terrenos baldíos, con el objetivo de cruzar el río y llegar a otro cantón: "ahora hemos perdido la libertad de veras, o somos libres, realmente" (Centeno, 2014, p. 83). En la huida, se encuentran con una cabeza humana sin cuerpo que refleja el destino que les espera si no logran salir. Los protagonistas tienen claro que, ante esa circunstancia, la única opción es escapar:

Si nos encuentran nos ejecutan. Arrastrarán nuestros cadáveres por las calles, atarán nuestras piernas en una de sus motos y nos exhibirán como trofeos, luego nos arrojarán al río y desapareceremos del paisaje y de la memoria de los peatones y de los hombres (Centeno, 2014, p. 87).

La idea de escapar con vida arroja un halo de esperanza al protagonista. Sabe que si logra salir del cantón en el que habita, podría, quizás, encontrarse con un mundo un poco más amable, menos violento, en el que no se le persiga ni se le conozca. Los personajes conocen de la existencia de otras urbanizaciones, que el país se dividió en cantones, que en cada cantón existen reglas diferentes, y que tal vez puedan llegar a un lugar donde se sientan conformes, "un lugar donde tengan algunos derechos, entre ellos el de no ser cazados o atropellados" (Centeno, 2014, p. 72).

El presente que imagina Centeno cumple con los criterios para identificar una distopía que Diana Palardy establece en Dystopian Impulses in Contemporary Peninsular Literature and Film (2018b). 
Según ella, una obra puede ser considerada distopía si responde afirmativamente a estas preguntas:

- ¿Se trata de una sociedad hipotética?

- Los individuos de esta sociedad (o de algún sector determinado de esta sociedad), ¿están oprimidos, incluso si no se dan cuenta de estarlo?

- En la obra, ¿se sugiere que el estado de la sociedad que se describe se debe a problemas sistémicos y de orden socio-político?

- Los problemas sistémicos y de orden socio-político subyacentes en la obra, ison realmente extrapolaciones de asuntos y desarrollos que no están siendo tratados de manera efectiva (o que no están siendo tratados en absoluto) en la sociedad del autor o director de la obra?

- ¿Se trata de una sociedad basada en la planificación estatal y que pretenda ser ideal para una parte o para la totalidad de sus ciudadanos, o que al menos pretenda ser mejor para ellos que las sociedades que la precedieron (en caso de que la sociedad en cuestión hubiera surgido como resultado de una guerra, de un desastre ecológico o de cualquier otro evento social traumático, por ejemplo)?

- ¿Tiene la obra, ya sea de forma implícita o explícita, una función admonitoria, es decir, de advertencia al lector o al espectador y de exhortación a solucionar problemas socio-políticos en el momento mismo de sus inicios y no cuando su desarrollo haya llegado a los extremos distópicos presentados, precisamente, en la obra?

- ¿Puede notarse una intención del autor o del director de hacer experimentar al lector o al espectador una especie de de-familiarización al introducirse en el mundo de la obra?

- ¿Puede notarse una intención del autor o del director de hacer que el lector o el espectador se cuestione los códigos morales de la sociedad de la obra?

- El comportamiento de los personajes, ies monitoreado y/o controlado o, por lo menos, los personajes sienten que lo es?

- ¿Hay algún personaje protagónico o importante que experimente un proceso de desilusión con respecto a su condición en la sociedad de la obra y que, en consecuencia, intente rebelarse contra el sistema? (Palardy, 2018a).

Según esto, Jinete a pie es una obra distópica, por cuanto se 
trata de una sociedad hipotética en la que hay individuos oprimidos debido a problemas sistémicos y de orden sociopolítico, que son extrapolaciones de la sociedad real del autor. Esa sociedad hipotética es una sociedad que pretende ser mejor para una parte de sus ciudadanos (los motorizados). La obra tiene una función admonitoria, o de advertencia al lector, e intenta hacer que se cuestionen los códigos morales de esa sociedad ficticia, en la que el comportamiento de los individuos es controlado y el personaje protagónico, en algún momento, se rebela contra el sistema.

\section{Sobre la novela como crítica política y social}

Annelis Oeyen señala, en Escrituras del derrumbe. Ciudades posapocalípticas: Marcelo Cohen y la narrativa argentina posdictatorial (2011), que la ficción postapocalíptica busca una estética capaz de recuperar la memoria del pasado, elaborar mecanismos de representación de una catástrofe que parece irrepresentable, reverberar las "imágenes de las ruinas" y los conflictos, malestares e incertidumbres del presente.

Como ya se ha dicho, las distopías suelen ser indisociables del contexto en el que se escriben. Jinete a pie tiene elementos propios de la Venezuela actual. Los motociclistas de la novela prefiguran a los grupos de civiles armados que van en moto, conocidos como "colectivos", afines al Gobierno de ese país. Centeno los radicaliza en la ficción. Toma un hecho reciente, el fallido golpe de Estado que sufrió el entonces presidente Hugo Chávez en abril de 2002, como punto de partida del colapso de la sociedad en la ficción:

Unos militares toman la plaza Altamira, exigen la renuncia del presidente, la gente sale a la calle y decretan el final del gobierno, hay bulla por todas partes, debería sumarme a algo, se suspenden los cursos, el país va a una huelga general, es un punto de vista dicen unos y salen otros a defender al presidente, a su revolución, cada noche hay enfrentamientos en las calles, marchas y contramarchas, un hombre pone una chaqueta militar, una boina negra con una estrella al centro, deja colgar un tabaco en su boca, sube a una moto, es un guerrillero motociclista, el primero de su estirpe y a él se suman otros, son los mismos motorizados que salieron un año antes cuando se habló de renuncia o de golpe de Estado, tienen una cara visible, un uniforme 
verde oliva, vienen los motociclistas y los motorizados de chamarras de camuflajes, ahora son escuadras y rodean a quienes creen enemigos, fábricas cerradas por el paro, acordonan a las empresas estatales del petróleo, son el músculo rugiente de la revolución y la defienden (Centeno, 2014, p. 35).

Algunas notas periodísticas explican el accionar y el funcionamiento de los "colectivos" en la Venezuela de hoy. Una investigación del New York Times en español señala que se tratan de civiles con entrenamiento militar que han sido armados por las autoridades, y que en algunos casos se financian por medio de actos delictivos como la extorsión, el contrabando y el narcotráfico, y que hoy en día desempeñan un papel importante en la represión a la disidencia al gobierno de Nicolás Maduro (Torres y Casey, 2017). En una entrevista al diario venezolano El Universal, el propio Centeno hace referencia a esas bandas de motoristas respaldados por el Estado:

Cuando Nicolás Maduro los llama sus "caballeros de hierro" les da una patente de corso. Si les doy impunidad, los convierto en un brazo delincuencial. No es una realidad posible pensar un mundo dominados por ellos, es una realidad que ya es. Ahora el problema es revertir la situación sin quitarles todos sus derechos (Centeno, como se cita en Fermín, 2014).

Jinete a pie, en gran medida, viene a ser una crítica a la libertad y el poder con que cuentan los "colectivos" en la Venezuela de hoy. La novela vislumbra un futuro en el que los motociclistas toman el control absoluto del país tras el crac, en el que atacan a todo aquel que no haga parte de su "raza". De este modo, Centeno hiperboliza un problema real que ya existe, con el fin de criticar la política oficial del actual proceso. Otro fragmento de la novela resalta el poder hegemónico que se ejerce:

Cuentan, y esos son cuentos de la memoria, que las motos asaltaron el poder, un día se desquiciaron los motociclistas y se lanzaron sobre todo lo extraño a su condición, fueron acciones osadas, a veces suicidas, al menos esa parte de la ciudad era de ellos. Hubo un momento muy trágico en la historia del poder motorizado, la época de los safaris. Estaban institucionalizados, cada cierto tiempo se organizaban partidas para exterminar, primero al resto de los vehículos, a los que insistían en ir por las avenidas a pesar de no estar permitido, a los osados que 
insistían en correr por las avenidas y las autopistas; y luego, a los peatones, ellos deben ir por las aceras o las calles laterales, abandonadas, por lotes de terrenos. Se establecieron límites, cotos. Más adelante, cuando desaparecieron los vehículos de cuatro ruedas, se regularizó la caza de peatones [...]. El tiempo pasó y hay pactos. Los peatones son tolerados. Los peatones deben evitar a las bandas de motos, incluso a los motociclistas solitarios. Ellos administrarán el pacto y se reservan el derecho a violentarlo y llamar a un safari (Centeno, 2014, pp. 10-11).

Ese pacto de la ficción, que viene a dar la ilusión de libertad, también prefigura los constantes intentos de diálogo entre oposición y Gobierno en las dos últimas décadas. Ya desde 2002, tras el mencionado golpe de Estado, ha habido diversas mesas de conversación entre ambos sectores para llegar a acuerdos momentáneos. En la novela, el pacto se termina de romper cuando Morel asesina a un motorizado, que ocasiona una persecución de la que se ve obligado a huir para mantenerse con vida.

En resumen, la distopía de Centeno establece una relación inseparable con el presente de Venezuela, su fragmentación y sus diversas formas de poder. Centeno, sin moralizaciones explícitas, hace evidente el diálogo de la literatura con su contexto. Así, Jinete a pie tiene características de dos de los diferentes tipos de distopías que el griego Antonis Balasopoulos establece en su ensayo "Anti-utopia and dystopia: Rethinking the generic field" (2011): la distopía de represión autoritaria, en la que se identifica al Estado como el principal culpable de la perversión del impulso utópico, y la distopía crítica, que ve el presente orden sociopolítico, tecnológico o ecológico como el principal problema relacionado con la catástrofe.

\section{Conclusiones}

Israel Centeno hace una analogía de la Venezuela actual a través de Jinete a pie. La distopía se manifiesta en la radicalización de los problemas de la sociedad del autor en un mundo en ruinas que surge después de un colapso gradual de la sociedad de la obra. En su novela se muestra a una Caracas postapocalíptica y panóptica —según los tipos de ciudades que Reati (2006) establece como pro- 
pios de la ficción prospectiva-, que resulta indisociable del contexto venezolano contemporáneo afectado por la crisis política y social.

La obra de Centeno cuenta con la mayoría de las características básicas que tiene ciertas novelas del género distópico: una sociedad hipotética en la que hay individuos sometidos y que, en un principio, pretende ser mejor que la anterior para la otra parte de esa sociedad.

Centeno toma posición con su obra: critica las políticas de poder del Estado venezolano. Su obra se suma a una lista de títulos que, mediante el género distópico, advierten al lector de lo que podría llegar a pasar si no se transforman las tendencias de la actualidad $\mathbf{C}$

\section{Referencias}

Agencia EFE. (2017, 28 de diciembre). Venezuela cierra el 2017 con 26.616 asesinatos bajo un escenario de crisis. Recuperado de https://www.efe.com/efe/america/ sociedad/venezuela-cierra-el-2017-con-26-616-asesinatos-bajo-un-escenario-decrisis/20000013-3478798.

Agencia EFE. (2018, 19 de mayo). Éxodo masivo de venezolanos profundiza problemas sociales en América. EFE. Recuperado de https:/www.efe.com/efe/america/sociedad/ exodo-sin-precedentes-de-venezolanos-profundiza-los-problemas-sociales-enamerica/20000013-3620709.

Angarita Trujillo, A. R. (2015). Los vengamientos del ejército justiciador. Caracas: El perro y la rana.

Balasopoulos, A. (2011). Anti-utopia and dystopia: Rethinking the generic field. En Utopia Project Archive, 2006-2010 (pp. 59-67). Atenas: Escuela de Bellas Artes.

Bradbury, R. (1982). Fahrenheit 451. Traducción de A. Crespo. Barcelona: Plaza \& Janes.

Butler, S. (2000). Erewhon o tras las montañas. Traducción de J. Martínez Lorente. Madrid: Cátedra.

Calatrava, J. (2010). El espacio utópico. Una conversación con Raymond Trousson. Minerva (14). Recuperado de http://www.circulobellasartes.com/revistaminerva/articulo. php?id=404.

Campanella, T. (1953). La ciudad del sol. Buenos Aires: Losada.

Campo, D. (2004). Éxodo al Pacífico. Caracas: Comala.

Casablanca, E. (2016). El infinito de la estupidez humana. Amazon.

Centeno, I. (1992). Calletania. Caracas: Monte Ávila Editores.

Centeno, I. (1993). El rabo del diablo y otros cuentos. Caracas: Eclepsidra. 
Centeno, I. (1996). Hilo de cometa y otras iniciaciones. Caracas: Planeta.

Centeno, I. (1999). Exilio en Bowery. New Jersey: Ediciones Nuevo Espacio.

Centeno, I. (2000). Criaturas de la noche. Caracas: Alfaguara.

Centeno, I. (2002). El complot. Caracas: Alfadil.

Centeno, I. (2004). La casa del dragón. Caracas: Alfadil.

Centeno, I. (2005). Bengala. Caracas: Norma.

Centeno, I. (2014). Jinete a pie. Caracas: Lector cómplice.

Chiappe, D. (2007). Entrevista a Mailer Daemon. Madrid: La fábrica.

Claeys, G. (2011). Utopía: historia de una idea. Madrid: Siruela.

Domingo, A. (2008). Descenso literario a los infiernos demográficos. Distopía y población. Barcelona: Anagrama.

El Nacional. (2016, 14 de abril). En 13 años de control de precios, 9 han sido de escasez de productos básicos. El Nacional. Recuperado de http://www.el-nacional.com/noticias/ economia/anos-control-precios-han-sido-escasez-productos-basicos_25823.

El Nacional. (2018, 16 de enero). ovcs: se registraron 9.787 protestas en Venezuela durante 2017. Recuperado de http://www.el-nacional.com/noticias/protestas/ovcs-registraron9787-protestas-venezuela-durante-2017_218862.

Erreguerena Albaitero, M. (2008). La distopía: una visión del futuro. Anuario de Investigación, 556-572.

Europa Press. (2018, 24 de julio). El FMI vaticina una inflación del 1.000.000\% para Venezuela en 2018. Recuperado de http://www.europapress.es/economia/macroeconomia-00338/ noticia-fmi-vaticina-inflacion-1000000-venezuela-2018-20180724101746.html.

Fermín, D. (2014, 25 de mayo). Venezuela hoy espanta. El Universal, p. D5.

Hernández, A. (2018). El juego del futuro vaticinado: estudio alegórico de Venezuela en la novela Nocturama. Saber-ULA, (37), 5-17. Recuperado de http://www.saber.ula.ve/ handle/123456789/45074

Herrera Luque, F. (1992). 1998. Caracas: Grijalbo.

León Madriz, F. (1933). El regreso de Eva. Caracas: La Esfera.

London, J. (1980). El talón de hierro. Traducción de M. Ruipérez. Madrid: Endymion.

Martorell Campos, F. (2015). Transformaciones de la utopía y la distopía en la modernidad. Aspectos ontológicos, epistemológicos y políticos (Tesis doctoral). Universidad de Valencia, Valencia.

Montenegro, R. (2017). La extraordinaria historia de la literatura fantástica en Venezuela. Tiempos oscuros (8), 165-224. Recuperado de http://www.servercronos.net/bloglgc/ media/blogs/tiempososcuros/PDF/Revista_Tiempos_Oscuros_008.pdf.

Moros Puentes, C. (1998). Dóctor. San Cristóbal: Componentes. 
Muñoz Arteaga, M. (2009). Repaso a la narrativa de Israel Centeno. Destiempos, 4(22), 47-54. Recuperado de http://www.destiempos.com/n22/marteaga.pdf.

Oeyen, A. (2011). Escrituras del derrumbe. Ciudades posapocalípticas: Marcelo Cohen y la narrativa argentina posdictatorial (Tesis doctoral). Universidad de Gent: Gent.

Orwell, G. (2003). 1984. Traducción de R. Vásquez Zamora. Barcelona: Planeta DeAgostini.

Palardy, D. (2018a). Criterios de identificación de distopías. Recuperado de https://bit. ly/2CdTPSS

Palardy, D. (2018b). Dystopian Impulses in Contemporary Peninsular Literature and Film. Basingstoke: Palgrave MacMillan.

Quintero, E. (2017). El amor es más frío que la muerte. Barcelona: Candaya.

Reati, F. (2006). Postales del porvenir: la literatura de anticipación en la Argentina neoliberal. Buenos Aires: Biblos.

Rojo, V. (2016). Las heridas de la narrativa venezolana contemporánea. Cuadernos de Literatura, 20 (40), 653-656. Recuperado de http://revistas.javeriana.edu.co/index.php/ cualit/article/view/17874.

Saldías, G. (2015). En el peor lugar posible: teoría de lo distópico y su presencia en la narrativa tardofranquista española (1965-1975) (Tesis doctoral). Universidad Autónoma de Barcelona, Barcelona.

Santaella, F. (2009). Las peripecias inéditas de Teófilus Jones. Caracas: Alfaguara.

Sargent, L. T. (1975). Utopia-The problem of definition. Extrapolation, 16(2), 135-148. DoI: 10.3828/extr.1975.16.2.137

Sojo Montes, R. (2016). Seguros de justicia, C. A. Caracas: от Editores.

Suárez, B. (2011). La representación de la ciudad y el discurso de la violencia en la literatura latinoamericana contemporánea: Medellín, Caracas y Río de Janeiro (Tesis doctoral). Universidad de Florida. Recuperado de http://ufdcimages.uflib.ufl.edu/UF/E0/04/27/53/00001/ suarez_b.pdf.

Torres, A. (2006). Nocturama. Caracas: Alfa.

Torres P. y Casey N. (2017, 22 de abril). Los colectivos venezolanos, las bandas de civiles armados que atacan a los manifestantes y defienden a Maduro. New York Times. Recuperado de https://www.nytimes.com/es/2017/04/22/colectivos-venezuela-nicolasmaduro.

Trousson, R. (1995). Historia de la literatura utópica. Viajes a países inexistentes. Barcelona: Península.

Volpe, A. (2016). El reino de arena. Caracas: от Editores.

Vonnegut, K. (2017). La pianola. Traducción de J. Álvarez Flores. Madrid: Hermida.

Wells, H. G. (2015). La máquina del tiempo. Traducción de J. Fernández y A. Ramos. Madrid: Cátedra. 